\title{
A concepção de qualidade educacional impulsio- nada pelas avaliações externas no estado de São Paulo
}

\author{
Fabiana Alvarenga Filipe \\ Regiane Helena Bertagna \\ Universidade Estadual "Júlio de Mesquita Filho" | Rio Claro
}

\section{Resumo}

Este artigo apresenta dados de pesquisa e visa analisar a concepção de qualidade educacional induzida pela sistemática de avaliação em larga escala adotada do estado de São Paulo. Com relação aos procedimentos metodológicos, insere-se na Abordagem Qualitativa (ANDRÉ, 2005) por meio da Pesquisa Bibliográfica sobre avaliação e qualidade educacional, Levantamento Documental e Análise de Conteúdo. Evidenciou-se que o ideário neoliberal que permeia a política educacional paulista, desde a década de 1990, induz a qualidade educacional a uma concepção reducionista, pautada na quantificação de resultados. A pesquisa possibilitou também a reflexão acerca da Avaliação Institucional Participativa e do conceito de Qualidade Negociada como caminho para alcançar a Qualidade Social da Educação.

Palavras-chave: Qualidade educacional. Avaliação em larga escala. Políticas educacionais.

\section{The conception of educational quality driven by external evaluations in the state of São Paulo}

\section{Abstract}

This article presents research data and aims to analyze the conception of educational quality induced by the large-scale evaluation system adopted in the state of São Paulo. Regarding the methodological procedures, it is inserted in the Qualitative Approach (ANDRÉ, 2005) through the Bibliographical Research on evaluation and educational quality, Documentary Survey and Content Analysis. It was evident that the neoliberal ideology that permeates the São Paulo educational policy, since the 1990s, induces educational quality to a reductionist conception, based on the quantification of results. The research also made possible the reflection on the Participatory Institutional Assessment and Negotiated Quality concept as a way to achieve Social Quality of Education. Keywords: Educational quality. Large-scale evaluation. Educational policies. 


\section{La concepción de calidad educacional impulsada por las evaluaciones externas en el estado de São Paulo}

\section{Resumen}

Este artículo presenta datos de investigación y busca analizar la concepción de calidad educativa inducida por la sistemática de evaluación a gran escala, adoptada en el estado de São Paulo. Con respecto a los procedimientos metodológicos, se inserta en el Enfoque Cualitativo (ANDRÉ, 2005) por medio de la Investigación Bibliográfica sobre evaluación y calidad educativa, Levantamiento Documental y Análisis de Contenido. Se evidenció que el ideario neoliberal que impregna la políitica educativa paulista, desde la década de 1990, induce la calidad educativa a una concepción reduccionista, pautada en la cuantificación de resultados. La investigación posibilitó también la reflexión acerca de la Evaluación Institucional Participativa y del concepto de Calidad Negociada como camino para alcanzar la Calidad Social de la Educación.

Palabras clave: Calidad educativa. Evaluación a gran escala. Políticas educativas.

\section{Contexto das avaliações em larga escala no estado de São Paulo}

Sabe-se que, desde meados da década de 1990, o estado de São Paulo está sendo governado pelo mesmo partido político, o Partido da Social Democracia Brasileira (PSDB). Em 1995, enquanto Fernando Henrique Cardoso assumia a presidência da república, Mário Covas tomava posse do governo do estado de São Paulo.

Russo (2014) assinala que foi no governo Fernando Henrique Cardoso que foi promovida a reforma educacional com base no modelo neoliberal e que tal reforma refletiu na políitica educacional do governo paulista, tendo em vista que ambos pertenciam ao mesmo partido políitico.

Dantas (2013) analisou a política educacional do estado de São Paulo e assinala que

De início o texto faz uma análise crítica da educação pública e de sua administração nos últimos anos enfatizando a ineficiência da própria Secretaria da Educação na condução dos serviços públicos, tidos como deteriorados, ineficazes e sem controle. 
Considera-se que a educação paulista passou, nos últimos vinte anos, por um processo de deterioração e de retrocesso (DANTAS, 2013, p. 39).

Dessa forma, a educação do estado estaria (per) seguindo o ideário neoliberal proposto por FHC em âmbito federal, que a partir da problemática da ineficiência do Estado propõe soluções pautadas nos parâmetros da gestão empresarial.

Lammoglia (2013, p. 104) afirma que com base no "diagnóstico" da ineficiência do sistema educacional paulista, ocorrido pelo "[...] gigantismo do sistema aliado à falta de mecanismos de controle; a centralização excessiva e a irracionalidade em relação ao quadro de funcionários [... $]^{\prime \prime}$ a receita para melhorar a "[...] eficiência da educação em São Paulo [...]" estava centrada na proposta de "[...] revisão do papel do Estado na prestação de serviços educacionais $[\ldots]^{\prime \prime}$.

Acerca das mudanças para reformar o Estado, a autora pontua que "[...] temos o incentivo à municipalização do ensino, com o interesse de descentralização, e a implantação do Sistema de Avaliação do Rendimento Escolar, o SARESP, como mecanismo de controle" (LAMMOGLIA, 2013, p. 105).

Com base no diagnóstico de que houve a expansão do ensino sem devida preocupação com a qualidade, o governo Covas tomou medidas estratégicas para solucionar o problema da baixa qualidade educacional, que "[...] contemplaram a racionalização do fluxo escolar, a instituição de mecanismos de avaliação de resultados e o aumento da autonomia administrativa, financeira e pedagógica das escolas" (DANTAS, 2013, p. 42, grifo nosso).

Para racionalização do fluxo escolar, foram implementados os Programas de Correção do Fluxo Escolar, Programa de Escola nas Férias e de Progressão Continuada, sendo este último, o que mais gerou críticas por eliminar a reprovação no ensino fundamental. O Programa Reorganização da Trajetória Escolar no Ensino Fundamental foi implementado por meio das Classes de Aceleração integradas às séries desse grau de ensino e, concomitantemente, foi implantada a recuperação nas férias.

No que tange à instituição de mecanismos de avaliação, em 1996 é criado o Sistema de Avaliação do Rendimento Escolar do Estado de São Paulo (SARESP) "[...] cujo objetivo anunciado foi a integração das ações escolares a partir do estabelecimento de um sistema criterioso de avaliação dos resultados 
da aprendizagem dos alunos e a criação de condições para que as escolas respondam por eles" (DANTAS, 2013, p. 44).

De acordo com Oliveira Júnior (2013, p. 40), "A entrada do SARESP com seus indicadores, juntamente com o escopo da progressão continuada na educação paulista, são elementos bem significativos na constituição e desenvolvimento de uma cultura avaliativa no estado de São Paulo." Mas, apesar de ser clara a utilizaçao do SARESP "[... ] como forma de ampliar as possibilidades avaliativas na escola [...]", "[...] a partir de suas ações e impactos, alguns autores questionam e/ou ponderam acerca dessa condição concernente ao desenvolvimento de uma cultura avaliativa nas escolas paulistas".

$\bigcirc$ autor assinala que a política do SARESP está circunscrita em três grandes momentos, no período compreendido entre 1996 e 2011 . O primeiro momento é designado pelo pesquisador como "Formação identitária no contexto do pioneirismo das avaliações em larga escala (1 996-2002)", e

[...] se caracterizou pela construção identitária, uma vez que esse sistema de avaliação se colocou como política educacional de avaliação capaz de contribuir para uma nova 'cultura de avaliação' no ensino de São Paulo, em busca da melhoria da qualidade educacional, no contexto, em ampla ascensão, da avaliação em larga escala no Brasil (OLIVEIRA JÚNIOR, 2013, p. 55-56).

segundo grande momento, designado por Oliveira Júnior (2013) como "Instabilidade do sistema no contexto da alternância no comando (2003 a 2007)".

[...] teve como características fundamentais a instabilidade na estrutura do sistema, marcado por muitas trocas de comando da Secretaria de educação. Passaram por esse período três secretários. Gabriel Chalita (2002-2006), a professora Maria Lucia Vasconcelos (2006-2007) e a ex-presidente do INEP Maria Helena Guimarães de Castro (2007-2009). Também fizeram parte desse período três governadores: Geraldo Alckmin (2003-2006), Cláudio Lembo (2006) e José Serra (2007-2010) IOLIVEIRA JÚNIOR, 2013 , p. 65, grifo nosso).

De acordo com o autor citado, "[...] essas trocas de comando, que geraram alguns desencontros, também foram responsáveis pela preparação para outra importante transformação do SARESP, iniciada em 2007 e efetivada 
no terceiro grande momento, a partir de 2008" IOLIVEIRA JÚNIOR, 2013 , p. 65), designado como "Estabilidade do sistema no contexto do hiperpragmatismo gerencial":

terceiro grande momento do SARESP está marcado por um importante processo de estabilização, a partir da reestruturação iniciada em 2007 e consolidada em 2008, sob o comando de Maria Helena Guimarães de Castro. Essa estabilidade alinha-se a um formato gerencial que atua, principalmente, com medidas consideradas aqui pragmáticas, em termos de eficiência das iniciativas governamentais, numa racionalidade essencialmente instrumental, com foco nos resultados dos alunos no SARESP, objetivando sua evolução (OLIVEIRA JúNIOR, 2013, p. 72).

Desta forma, o contexto de emergência e consolidação da implantação das avaliações em larga escala no estado de São Paulo, instigou a análise da concepção de qualidade educacional induzida pela sistemática de avaliação em larga escala adotada pelo referido estado, objetivo deste trabalho.

\section{A trajetória da pesquisa}

A investigação ocorreu no âmbito da abordagem qualitativa, visto que é fundamentada "[...] numa perspectiva que valoriza o papel ativo do sujeito no processo de produção de conhecimento e que concebe a realidade como uma construção social [...]" (ANDRÉ, 2005, p. 47). A pesquisa é documental, valendo-se "[...] de materiais que não receberam ainda um tratamento analítico [...]" (GL, 2008, p. 51 ) e é também do tipo bibliográfica, aquela "[...] desenvolvida a partir de material já elaborado, constituído principalmente de livros e artigos científicos" (GIL, 2008, p. 50).

Foi realizado levantamento de Leis Ordinárias, Leis Complementares, Decretos e Resoluções do período compreendido entre 2008 e 2014, que pudessem, de alguma forma, auxiliar na compreensão da concepção de qualidade educacional induzida pelas avaliações em larga escala no estado de São Paulo.

Com a revisão bibliográfica e com o levantamento dos documentos, necessários ao desenvolvimento da pesquisa, os dados foram tratados por meio da análise de conteúdo que é definida por 
Um conjunto de técnicas de análise das comunicações visando obter, por procedimentos sistemáticos e objetivos de descrição do conteúdo das mensagens, indicadores (quantitativos ou não) que permitam a inferência de conhecimentos relativos às condições de produção/recepção (variáveis inferidas) destas mensagens (BARDIN, 2010, p. 44).

No total, foram analisados 77 documentos oficiais, sendo que, durante as leituras dos dispositivos legais, foram emergindo as Unidades de Registro Temáticas/categorias (BARDIN, 2010). $\bigcirc$ Quadro 1 traz a distribuição das quantidades e tipos de documentos por categoria.

Quadro 1

Quantidades e tipos de documento por categoria

\begin{tabular}{|c|c|c|c|c|c|c|}
\hline Categoria & Lei Ordinária & Lei Comp. & Decreto & Resolução & Outros Docs. & Total \\
\hline Participação & 1 & 0 & 3 & 6 & 0 & 10 \\
\hline Avaliação & 0 & 0 & 3 & 4 & 0 & 7 \\
\hline Qualidade & 0 & 3 & 21 & 35 & 1 & 60 \\
\hline \multicolumn{7}{|c|}{ Total de Documentos } \\
\hline
\end{tabular}

Fonte: Dados de pesquisa elaborados pelas autoras.

Vale ressaltar que os documentos foram pesquisados no site da Assembleia Legislativa do estado de São Paulo (http:/ / www.al.sp.gov.br// e no site da Secretaria de Educação do estado de São Paulo (www.educacao. sp.gov.br).

\section{A qualidade educacional evidenciada pelos documentos pesquisados}

\section{Quem participa e para quê?}

objetivo deste tópico é destacar alguns pontos das análises dos documentos da Categoria "Participação" (apresentados no quadro 2), visto que, em nossa compreensão, a participação do coletivo da escola é primordial para construção da qualidade social. 


\section{Quadro 2}

\section{Categoria Participação - Documentos}

\begin{tabular}{|l|l|}
\hline Lei Ordinária & $14.689 / 2012$ \\
\hline Decretos & $53.667 / 2008,51.672 / 2007,52.221 / 2007$ \\
\hline Resoluções SE & $18 / 2010,22 / 2011,51 / 2012,21 / 2012,09 / 2013,55 / 2014$. \\
\hline
\end{tabular}

Os documentos constantes do quadro acima trouxeram alguns pontos relevantes para compreensão do nosso problema de pesquisa. São eles:

- Presença do controle social dos recursos educacionais

- Criação de uma "cultura da participação"

- Democracia

- Diálogo

- Debates

- Abertura para propostas

- Qualidade Social da Educação

- Apoio a ações de voluntariado e solidariedade

- Abertura para convênios e parcerias que abrangem o setor privado

- Participação de Estudantes Universitários que podem atuar de acordo, não somente com seus cursos de graduação, mas também conforme as suas habilidades pessoais.

Alguns elementos elencados no conjunto de normas dessa categoria foram muito significativos ao propiciarem possibilidades para que, por meio da participação dos agentes escolares, a educação do estado de São Paulo percorra o caminho rumo à efetividade da qualidade educacional. Entretanto, alguns elementos apresentam outras possibilidades que merecem e inspiram cautela, como a compreensão de participação como incentivo ao voluntariado e parcerias com entidades privadas, pois essas possibilidades ensejam estratégias para a inserção do setor privado na esfera pública. Isso pode caracterizar a desresponsabilização do Estado e a consequente abertura para que a lógica do mercado, do setor empresarial introduza regras em um espaço que é direito social. 
Dessa forma, compreende-se que a problemática que permeia a categoria "Participação" está localizada em seu conceito, ou seja, enquanto se entende que a participação está relacionada à gestão democrática da educação e, portanto, da participação dos agentes escolares na construção da qualidade social, que está ligada a fatores internos e externos, conforme proposto por Silva (2009), e que é de responsabilidade do Estado. A legislação ora analisada abre possibilidades para que a responsabilidade educacional seja repassada para o setor privado. Como exemplo, é oportuno citar a Resolução SE 18, de 5 de fevereiro de 2010 que traz a importância de desenvolver uma cultura de participação, dando abertura para participação da comunidade escolar, mas, ao mesmo tempo, abre possibilidades para convênios e parcerias com empresas privadas (SÃO PAULO, 2010).

Convém ressaltar, ainda, a compreensão de que os espaços de participação previstos nas normas analisadas, como, por exemplo, o "Conselho de Acompanhamento e Controle Social sobre a distribuição, a transferência e a aplicação dos recursos [...]" do Fundo de Manutenção e Desenvolvimento da Educação Básica e de Valorização dos Profissionais da Educação - FUNDEB (SÃO PAULO, 2008a, p. 3), instituído pelo Decreto 53.667/2008, devem ser ocupados e utilizados pela coletividade da escola, na perspectiva da qualidade negociada (BONDIOLl, 2004) entre os diferentes participantes da comunidade escolar e, entre estes e o poder público responsável.

Nesse ponto, é pertinente ponderar que, apesar de o conjunto de normas da Unidade de Registro trazer pontos que não vão ao encontro da qualidade social, como, por exemplo, a possibilidade de interpenetração do setor privado no público, compreende-se que há, também espaços de participação onde a luta para a construção de uma educação de qualidade social pode se fazer permear.

\section{Para que avaliar?}

Na categoria "Avaliação" foram analisados os documentos apresentados no Quadro 3. 
A concepção de qualidade educacional impulsionada pelas avaliações externas no estado de São Paulo

\section{Quadro 3}

Categoria Avaliação - Documentos

\begin{tabular}{|l|c|}
\hline Decretos & $54.253 / 2009,55.864 / 2010,61.307 / 2015$ \\
\hline Resoluções SE & $42 / 2009,74 / 2012,41 / 2014,73 / 2014$. \\
\hline
\end{tabular}

Os documentos, apresentados no Quadro acima, revelaram alguns pontos que merecem destaque:

- A criação do CIMA - Comitê Central de Informação, Monitoramento e Avaliação Educacional, devido à necessidade de avaliar, sistematizar e disseminar resultados para formulação de políticas educacionais, sendo, portanto, o porta-voz das informações "objetivas e confiáveis" sobre o desempenho educacional. Esse comitê ganha também, em 2012 , a responsabilidade pelo censo escolar.

- O reconhecimento do SARESP como fonte para tomada de decisões de educadores e como importante indicador de qualidade, por compor o IDESP.

- A reorganização do Ensino Fundamental em Regime de Progressão Continuada.

- O enaltecimento dos resultados das avaliações externas, pela Resolução SE 73, de 29 de dezembro de 2014 ao afirmar que eles"[...] confirmam as possibilidades de aumento da eficácia e eficiência do redimensionamento dos ciclos do Ensino Fundamental, com flexibilização dos tempos de aprendizagem e diversificação dos mecanismos de apoio [...]" |SÃO PAULO, 2014a, grifo nosso).

Acerca do CIMA, há o entendimento de que ele exerce um importante papel de organização e de execução da política de avaliação do estado de São Paulo. É por meio desse comitê que os resultados são sistematizados e disseminados para que as políticas sejam formuladas. Nesse sentido, há um enaltecimento dos resultados do SARESP, que compõem o IDESP e que possibilitam, segundo os documentos, a melhoria no que tange ao redimensionamento dos ciclos.

Pertinente a Progressão Continuada sabe-se que esse é um mecanismo que tem potencialidade para diminuir a exclusão e a seletividade nas escolas, 
visto que o seu objetivo é flexibilizar o tempo de aprendizagem, de acordo com o desenvolvimento de cada aluno. No entanto, Bertagna (2010, p. 196), ao apresentar as conclusões de sua pesquisa, constatou que "[...] a prática avaliativa exercida pelos professores sofreu alterações quanto aos instrumentos de avaliação usados, mas pouco se pôde perceber em relação à mudança na função que a avaliação historicamente exerceu na escola, como foi enunciado nos textos oficiais".

De acordo com a autora, "[...] pouco se conseguiu avançar no sentido de mudança de concepção de avaliação, ou mesmo na cultura avaliativa e escolar, como a proposta do regime de progressão continuada apontava nos documentos oficiais" (BERTAGNA, 2010, p. 197).

Dessa maneira, é possível afirmar que os objetivos declarados do Regime de Progressão Continuada não se efetivam no estado de São Paulo, ou seja,

Ao descrever como opera na realidade a avaliação informal e formal e como ela mantém sua função de selecionar os indivíduos e classifica-los, pode-se afirmar que a progressão continuada dificilmente se efetivará nessas condições; ela poderá apenas aproximar-se de uma aprovação automática que não responde às expectativas propostas nos documentos oficiais, muito menos, ao ideal de qualidade de ensino, ainda que resolva em parte o problema dos índices estatísticos relativos à reprovação (BERTAGNA, 2010 , p. 208, grifo da autora).

Segundo a referida autora, o problema dos índices estatísticos é resolvido "em parte", porque

[...] além da exclusão [...] no interior do sistema escolar, para aqueles que conseguiram o acesso [...] e conseguem nele permanecer $[\ldots]$, há outras que não foram aqui abordadas: a exclusão antes da escola e a "exclusão oficial", as taxas de evasão escolar oficiais, que não deixam de representar uma outra forma de exclusão (BERTAGNA, 2010, p. 208).

Arcas (2010), ao analisar as implicações do SARESP e do Regime de Progressão Continuada na avaliação escolar, de acordo com depoimentos de Professores Coordenadores pontua que houve mudanças nas práticas avaliativas com a progressão continuada, mas que essa é incômoda aos professores, 
pelo fato de que eles possuem dificuldades em compreendê-la e por sentirem que os alunos não se dedicam como antes, e ainda, por ocorrer a reprovação apenas ao final de cada ciclo. Foi revelado também que há professores que se esforçam para compreender a progressão continuada e promover mudanças em função dela.

Já o SARESP influencia mais o trabalho pedagógico, havendo uma tendência cada vez maior de sua utilização no currículo e no planejamento escolar, que, de acordo com o autor, ocorre em parte, por conta do enfraquecimento da política de ciclos e progressão continuada (ARCAS, 2010). Dessa forma,

A centralidade do objetivo da avaliação deslocou-se, em certa medida, da decisão sobre a aprovação/reprovação para o Saresp. Essa situação revela que ele é, atualmente, o mais potente indutor e implementador de políticas educacionais no Estado de São Paulo (ARCAS, 2010, p. 486).

Em face do exposto, é possível afirmar que o conjunto de normas constante da Unidade de Registro "Avaliação" é composto por dispositivos que 198 representam avanços, no sentido de uma política que visa combater a seletividade, como é o caso da Progressão Continuada, mas que estão alicerçadas em uma política que valoriza os resultados das avaliações.

Outro aspecto interessante que emergiu nessa unidade está relacionado ao SARESP, instituído em 1996 e em funcionamento. Seus resultados são importantes para a composição do IDESP, instituído em 2007; nos documentos analisados, se observou que há maior recorrência da menção ao índice do que ao sistema de avaliação.

\section{Que qualidade está sendo impulsionada?}

Esta seção tem o objetivo de discutir acerca da concepção de qualidade educacional que está sendo impulsionada pelas iniciativas de avaliação em larga escala no estado de São Paulo, por meio dos documentos elencados no Quadro 4. 


\section{Quadro 4}

\section{Categoria Qualidade - Documentos}

\begin{tabular}{|c|c|}
\hline Leis Complementares & $1.078 / 2008,1.086 / 2009,1.087 / 2009$ \\
\hline Decretos & $\begin{array}{c}54.043 / 2009,54.173 / 2009,54.174 / 2009,54.277 / 2009, \\
54.278 / 2009,54.702 / 2009,54.553 / 2009,55.545 / 2010, \\
55.727 / 2010,56.125 / 2010,56.872 / 2011,57.195 / 2011, \\
57.571 / 2011,57.791 / 2012,57.925 / 2012,57.931 / 2012, \\
57.978 / 2012,59.018 / 2013,59.863 / 2013,59.150 / 2013, \\
60.299 / 2014 .\end{array}$ \\
\hline Resoluções SE & $\begin{array}{l}\text { SE } 86 / 2007,74 / 2008,76 / 2008,86 / 2008,96 / 2008, \\
21 / 2009,22 / 2009,23 / 2009,25 / 2009,26 / 2009,66 / 2009, \\
31 / 2010,32 / 2010,34 / 2010,43 / 2010,45 / 2010,63 / 2010, \\
20 / 2011,21 / 2011,81 / 2011,35 / 2012,36 / 2012,37 / 2012, \\
41 / 2012,87 / 2012,11 / 2013,21 / 2013,36 / 2013,67 / 2013, \\
68 / 2013,88 / 2013,3 / 2014,17 / 2014,21 / 2014,71 / 2014 .\end{array}$ \\
\hline Outro Documento & Programa de Qualidade da Escola. Nota Técnica \\
\hline
\end{tabular}

Fonte: Dados de pesquisa elaborados pelas autoras.

A categoria "Qualidade" agrupa o maior número de documentos analisados, merecendo destaque, o lançamento do PQE e a criação do IDESP (que utiliza os resultados do SARESP em sua composição), sua vinculação à Proposta Curricular, a política de Bonificação por Resultados e, ao Programa Educação Compromisso de São Paulo.

A Resolução SE 74 de 6 de novembro de 2008, cria o IDESP e o PQE com o propósito de melhorar os serviços educacionais e, também, subsidiar as ações, visando promover a melhoria da qualidade educacional (SÃO PAULO, 2008 b). Entretanto, constata-se que tal norma traz consigo uma concepção reducionista de qualidade educacional, ao restringi-la à necessidade de diagnósticos e metas quantificáveis para cumprimento nas unidades escolares.

Cabe ressaltar, ainda, que a mesma norma vincula o cumprimento de metas à bonificação por desempenho ou por mérito, tanto que pouco mais de um mês da instituição do IDESP, é promulgada a Lei n ${ }^{\circ} 1.078$, de 14 de dezembro de 2008, que dispõe sobre a BR (SÃO PAULO, 2008c).

Dessa forma:

[...] a concessão de bônus para os professores depende do IDESP das escolas. Como um importante componente do IDESP é o SARESP, e considerando que as questões que são cobradas 
no SARESP estão vinculadas ao currículo padronizado da SEE/ $\mathrm{SP}$, é possível afirmar que quanto mais o ensino se aproximar do 'Caderno do Professor' e da Proposta Curricular, maiores as chances dos alunos obterem boas notas no SARESP e elevar o IDESP da escola, o que contribuiria para o recebimento do bônus por parte dos professores (LOUREIRO, 201 1, p. 96-97).

Barros, Tavares e Massei (2009) defendem a política de Bonificação por Resultados - BR do estado de São Paulo e afirmam que

Essa políica faz parte do amplo projeto educacional do Estado de São Paulo, cuja missão é promover a mudança de cultura organizacional das instituições estaduais de ensino, de modo a incorporar a análise dos resultados das avaliações e dos indicadores como instrumento de tomada de decisões no campo pedagógico e administrativo em direção ao cumprimento de metas de melhoria de qualidade do ensino (BARROS; TAVARES; MASSEl, 2009, p. 54).

Os autores mencionados possuem a compreensão de que a política de BR faz parte de um projeto maior de alteração da cultura organizacional e que, sendo cumpridas as metas, a unidade escolar será de qualidade. 200 Entretanto, as evidências dos documentos analisados parecem encaminhar para a compreensão de que essa política faz parte de um projeto que possui o interesse de alinhar a escola ao funcionamento do mercado, regulada por metas, com distribuição de prêmios para os "melhores profissionais".

Da mesma forma que Barros, Tavares e Massei (2009), Castro (2009) também concorda com a política de BR por considerá-la como incentivo às unidades escolares "mais" esforçadas. Nesse sentido, a autora afirma que

O novo SARESP [revisto em 2007] e o IDESP transformaram-se na base de sustentação da política de incentivos às equipes das escolas com o objetivo de reconhecer o esforço de cada unidade para melhorar seu desempenho, independente da fantástica diversidade das 5.500 escolas da rede estadual paulista (CASTRO, 2009, p. 289, grifo nosso).

Como se pode observar, Castro (2009) entende que independentemente das diferenças e dos determinantes intra e extraescolares, é possível que haja esforço visando melhorar o desempenho das escolas, sendo nosso posicionamento contrário ao da autora. 
É possível afirmar ainda, por meio dos documentos analisados, que a competitividade é impulsionada no sistema educacional pela política de BR; e, nesse contexto, as avaliações, em larga escala, assumem a função de controle, já que fazem parte do cálculo do IDESP, que classificará as escolas e, de acordo com a política educacional do estado de São Paulo, premiará os melhores.

Para que as metas sejam cumpridas, no dia seguinte da publicação da norma que instituiu o IDESP e o PQE, é publicada a Resolução SE 76, de 7 de novembro de 2008 (SÃO PAULO, 2008d), que institui a "Proposta Curricular", $e^{\text {"[ }}[.$.$] trouxe no bojo o vício autoritário das políticas educacionais$ e foi visto como esvaziador do trabalho docente, significando falta de autoria e de autonomia dos profissionais da Educação" (DANTAS, 2013, p. 116).

Não se deve deixar de destacar aqui o Programa Educação Compromisso de São Paulo, que traz consigo diretrizes que abordam questões como a valorização do magistério, a melhoria da qualidade do ensino médio e o atendimento prioritário às escolas que possuem alunos que não apresentaram bom desempenho no SARESP. O referido programa aponta, claramente, a concepção de avaliação em larga escala como instrumento que referencia a qualidade, reduzindo-a ao desempenho exigido nessas avaliações.

Com a implementação do Programa Educação Compromisso de São Paulo, vários outros programas vão sendo instituídos para the dar aplicabilidade, tais como: o Programa Residência Educacional, o Programa Ensino Médio Inovador - ProEMl e o Programa Novas Tecnologias - Novas Possibilidades.

Dantas, ao discutir o Programa Educação Compromisso de São Paulo, assinala que

Na realidade, a intenção declarada fora a construção de um plano de ação, envolvendo o Governo, a Secretaria da Educação e a sociedade civil, com o objetivo de desenhar um plano estratégico de longo prazo, isto é, um plano que transcenda o governo atual, lançando diretrizes a serem seguidas pela Rede Estadual paulista até 2030, isto é, um Plano de Estado (DANTAS, 2013, p. 91 ).

A autora afirma ainda que "[...] todas as ações previstas para os próximos anos estão contempladas nos documentos elaborados pela Consultoria Americana Mckinsey \& Company" (DANTAS, 2013, p. 91) e, considerando 
que os relatórios, elaborados pela Consultoria, teriam o diagnóstico da situação educacional do estado de São Paulo, a pesquisadora pontua que

Diante dessa situação, pareceu-nos estranho as restrições de uso dos Relatórios da Mckinsey \& Company, visto que ele fora um presente dos empresários para a SEE/SP. Assim, a interdição pública dos planos traçados para a educação do Estado de São Paulo vão de encontro com uma política de transparência e participação dos profissionais da educação na construção de um plano de ação coeso e consensual. Na realidade, todas as ações já estavam estrategicamente planejadas, com detalhamento de todas as intervenções, marcos de implementação, macroestratégias etc (DANTAS, 2013, p. 92).

Outro ponto a ser destacado é que o Programa Educação Compromisso de São Paulo,

[...] teve como colaboradores para a sua construção não só o apoio de suas diversas áreas técnicas, mas também levou em conta as propostas e sugestões da própria rede estadual de ensino, cuja participação foi propiciada nas reuniões do Secretário da Educação, Profo Herman Voorwald e do Secretário-Adjunto, João Cardoso de Palma Filho com as 91 diretorias de ensino de todo o Estado, divididas em 15 pólos [...] (DANTAS, 2013, p. 93).

Além da participação dos atores acima mencionados, a autora assinala que

Outros atores estavam envolvidos na construção do programa Educação Compromisso de São Paulo, a saber: Fundação Natura, Fundação Victor Civita, Fundação Lemann, MSC participações, Instituto Unibanco, Comunidade Educativa Cedac, Instituto Hedging-Griffo, Fundação Itaú Social, Itaú BBA, Iguatemi, Santander, Tellus, Parceiros da Educação, Fundação Educar Dpaschoal, Fundação Bradesco, Instituto de Co-Responsabilidade pela Educação (lce), Centro de Estudos e Pesquisas em Educação, Cultura e Ação Comunitária (Cenpec), Instituto Península, Instituto Arymax e consultoria internacional Mckinsey \& Company lOverall Coordination) (DANTAS, 2013, p. 93).

A mobilização da sociedade civil pela educação é um dos pontos principais do Programa e, por conta disso, 
[...] a primeira iniciativa para alavancar esse envolvimento e a participação foi o chamamento dos 185 mil pais de alunos, em 1.934 escolas estaduais que possuíam o Programa Escola da Família, para participarem de um dia de discussões. Os dados divulgados pela SEE apontaram que 95 mil sugestões foram elaboradas e utilizadas como subsídio para o programa (DANTAS, 2013, p. 93).

A "[...] viabilização de mecanismos organizacionais e financeiros para operacionalizar o Programa" é "[...] outro pilar do Programa Educação Compromisso de São Paulo [...]" (DANTAS, 2013, p. 93) e, para tanto, são previstas parcerias para fomentar a educação. Exemplo disso é a proposta

[...] parceria público-privada, via Comunicado SE publicado em 4 de abril de 2012, em que houve o chamamento público n 003/2012 do Conselho Gestor do Programa Estadual de parcerias público-privada - CGPPP do Estado de São Paulo para apresentação de eventuais agentes interessados da iniciativa privada, de estudos técnicos e modelagem do projeto de Parceria Público-Privada (PPP) Aula Interativa (DANTAS, 2013, p. 93).

Com o projeto Aula Interativa "[...] tornou-se possível que serviços considerados privativos do Estado sejam transferidos pela iniciativa privada. Eis a lógica da parceria público-privada, materializada [...]". Dessa maneira, enquanto a SEE-SP considera que "[...] o objetivo do projeto é contribuir para melhorar as condições de ensino e aprendizagem por meio do uso de tecnologias em sala de aula [...], para estudiosos da política educacional, muitas dessas parcerias são, de fato, privatizações, pois enfraquecem o poder público e transferem o poder de decisão para instituições e empresas privadas (DANTAS, 2013, p. 109).

Em face do exposto, é possível questionar se tal Programa, que declara como objetivo melhorar a qualidade do ensino paulista, não favorece e incentiva a participação do setor privado na esfera pública, de forma a ocorrer a desresponsabilização do Estado. 


\section{Evidências e possibilidades: da concepção quantitativa de qualidade à avaliação como exercício coletivo}

Diante do exposto nas três Categorias analisadas, assinalam-se alguns pontos que contribuem para a discussão deste trabalho.

Primeiramente, é válido destacar que os documentos analisados evidenciam uma concepção de participação, contendo elementos que possibilitam a participação dos atores escolares em decisões que podem trazer proposições com transformações positivas para a unidade escolar, mas, contraditoriamente, essa concepção de participação pode, por exemplo, ampliar a inserção do setor privado na esfera pública, consequentemente, ocorrendo a desresponsabilização do Estado e a entrada da lógica mercadológica no espaço público. Isso deve ser analisado com cautela quando se trata de direitos sociais.

Os documentos analisados também evidenciam que o SARESP ganha destaque a partir da introdução do IDESP; esse último, sendo utilizado para a bonificação dos profissionais, acaba por induzir a qualidade educacional a uma concepção pautada na quantificação de resultados, em que o índice diz se a escola é de boa qualidade ou não e assim, se distribui prêmios e sanções entre os profissionais da educação. Nesse contexto, a Proposta Curricular impulsiona o alcance de metas, podendo trazer alterações na organização do trabalho escolar, principalmente a padronização de conteúdos em função das avaliações externas.

Dessa forma, a proposta atual do SARESP, atrelada ao Currículo e a uma política de bonificação, carrega consigo uma concepção que facilita e naturaliza uma ideia de qualidade educacional, alavancando os princípios de mercado, com base em uma lógica empresarial, tais como: competir, classificar, premiar/punir indivíduos e escolas para responsabilizá-las, sob o discurso da prestação de contas à sociedade, sendo o CIMA, o comitê que divulga os resultados sobre o desempenho educacional.

Nesse sentido, Afonso (2000, p. 44) esclarece que "[...] a emergência de políticas neoliberais e neoconservadoras veio dar novo impulso aos mecanismos de responsabilização em grande medida porque se tornou evidente a convergência de valores entre alguns modelos de prestação de contas e os pressupostos daquelas políticas [... $]^{\prime \prime}$. 
Vale, ainda, salientar que ações com potencialidade para otimizar a qualidade educacional, como, por exemplo, o Regime de Progressão Continuada - que representa um avanço conceitual nas políticas educacionais do estado de São Paulo, no que tange aos aspectos de reprovação e exclusão - são abaladas diante da centralidade das avaliações em larga escala, visto que, como apontado por Bertagna (2010) e Arcas (2010), existem alterações nos instrumentos avaliativos, sem, contudo, alterar, de fato, a concepção de avaliação.

Ao discutir as ações do estado de São Paulo para implantação do modelo gerencial, Oliveira Júnior assinala que

Para atender a esse desígnio e sob as bandeiras revitalizadas da eficiência, da prestação de contas e da equidade, o governo investe em medidas para envolver e aprimorar as relações de vários públicos do ambiente educacional. Daí a ações mais efetivas para participação dos pais em dias de SARESP, da política de bonificação por mérito aperfeiçoada, da intensificação na utilização de tecnologias comunicacionais e das premiações aos alunos que participam dessa avaliação. Destacamos também a abrangência de todas as áreas curriculares em suas avaliações, criação de matrizes de referência próprias de avaliação, o lançamento do Programa de Qualidade da Escola (PQE) e, junto com ele, a criação do Índice de Desenvolvimento Educacional de São Paulo (IDESP) [...] (OLIVEIRA JÚNIOR, 2013, p. 72).

Dessa forma, "A elaboração da Proposta Curricular, a criação do IDESP e a articulação da política de bônus-mérito com grande parte dos projetos da SEE/SP podem ser vistos como expressão do aprimoramento do controle das políticas educacionais neoliberais no Estado de São Paulo" (LOUREIRO, 2011 , p. 401.

Outro ponto importante a ser assinalado é que a centralidade das avaliações, em larga escala, pode favorecer a inserção da lógica da gestão empresarial, oriunda do setor privado na esfera pública.

Nesse ponto, torna-se necessário trazer as discussões realizadas por Freitas (2012), acerca da interligação entre a responsabilização, meritocracia e privatização. Entende-se, pois, que a relação entre os resultados das avaliações em larga escala, o estabelecimento de metas para o IDESP e a Proposta 
Curricular podem impulsionar o setor público a adotar a lógica de gestão privada nas unidades de ensino.

Nesse sentido, existe a compreensão de que a responsabilização, possibilitada pelo não cumprimento das metas estabelecidas, é, de acordo com Freitas (2012, p. 346), legitimada pela meritocracia, que, por sua vez, possui o objetivo de "[...] desenvolver novas formas de privatização do público [...]", para que se constitua o espaço "público não estatal", oposto ao espaço "público estatal".

Depreende-se do exposto que as avaliações, em larga escala, a partir das formas de utilização previstas nos documentos oficiais do estado de São Paulo, como por exemplo, consta da Lei n 1.078/2008 que institui a BR, estão induzindo a qualidade educacional a uma concepção mercadológica, que centraliza, segundo os documentos, a ideia de qualidade pautada em quantidade, competição e premiação, desconsiderando outros determinantes da qualidade educacional.

Nesse sentido, não são garantidas, por exemplo, a quantidade adequada de alunos por sala de aula, a formação e a valorização do magistério, sendo que essa última tem sido considerada pelos documentos como uma tarefa cumprida por meio da BR.

Importante ressaltar, também, que Sousa, Maia e Haas (2014) analisaram os resultados do Índice de Desenvolvimento da Educação do Estado de São Paulo - IDESP de 41 unidades da rede pública de um município da Grande São Paulo, no período de 2008 a 2012, trazendo as metas estabelecidas, as variações do índice ano a ano e o recebimento ou não da bonificação.

Os dados da pesquisa apontam oscilações no desempenho das escolas no período analisado, entretanto, como o IDESP é recalculado anualmente, "[...] houve bonificação em 2012 para 22 escolas que apresentaram, nesse ano, desempenho inferior ao de 2008" (SOUSA; MAIA; HAAS, 2014, p, 200). Nesse sentido, as autoras afirmam que "essa variação no cálculo e recálculo das metas, bem como nas bonificações com base no IDESP alcançado, colocam em questão a consistência dos resultados e a pertinência dessa iniciativa de política educacional"

Os dados apresentados pelas autoras indicam que

[...] o cumprimento de metas anuais não necessariamente representa melhoria de desempenho da escola; além disso, nem sempre 
a premiação recebida pela escola evidencia o aprimoramento de seu desempenho no decorrer dos anos. A focalização na alteração de desempenho anual e a correspondente premiação parecem iniciativas equivocadas, que não induzem a uma melhoria sustentada e cumulativa (SOUSA; MAIA; HAAS, 2014, p. 203).

Nesse sentindo, ainda que o IDESP seja tomado como referência de qualidade, o estudo acima mencionado aponta que não há avanços no sentido de melhoria do índice, tendo em vista que

$\bigcirc$ procedimento de recalcular as metas, alicerçado na ideia de considerar o processo de desenvolvimento de cada escola e de cuidar para que as metas sejam realistas, pode estar induzindo as escolas a acatarem a ideia de que resultados imediatos - por serem premiados - são mais relevantes do que o alcance de metas de longo prazo, o que as levaria a caminhar em sentido contrário ao da proposta inicial, que visava ao alcance de metas predeterminadas até 2030 (SOUSA; MAIA; HAAS, 2014, p. 205).

Dessa forma, além de entendimento de que o IDESP não expressa todas as dimensões da qualidade educacional, é possível afirmar que o recálculo do índice e a busca imediata de resultados para que haja bonificação, fazem com que as metas a longo prazo não sejam relevadas.

Em face das evidências apontadas, é necessário esclarecer que a defesa não é em favor da extinção das avaliações de sistemas, mas sim, pela sua utilização de uma forma diferente, que possibilite à instituição se apropriar dos dados e com base neles e não somente com eles, possa se transformar, ou seja, "[...] não basta o dado do desempenho do aluno ou do professor coletado em um teste ou questionário e seus fatores associados. É preciso que o dado seja "reconhecido" como "pertencendo" à escola" (FREITAS; SORDI; MALAVASI; FREITAS, 2012, p. 48), para que a instituição possa utilizá-los no momento da autoavaliação. Dessa forma, os resultados dos testes poderão auxiliar o coletivo escolar na identificação de suas dificuldades e também dos progressos da escola, auxiliando no trabalho pedagógico e no desenvolvimento dos alunos.

Tem-se a clareza de que é necessário que ocorra uma mudança na forma de "olhar" e utilizar os dados das avaliações em larga escala e que a 
qualidade social da educação é o caminho para que todos possam desfrutar de uma formação humana emancipatória.

A qualidade social, de acordo com Silva (2009, p. 223), "[...] não se restringe a fórmulas matemáticas, tampouco a resultados estabelecidos a priori e a medidas lineares descontextualizadas". Uma escola de qualidade social

[...] é aquela que atenta para um conjunto de elementos e dimensões socioeconômicas e culturais que circundam o modo de viver e as expectativas das famílias e de estudantes em relação à educação; que busca compreender as políticas governamentais, os projetos sociais e ambientais em seu sentido político, voltados para o bem comum; que luta por financiamento adequado, pelo reconhecimento social e valorização dos trabalhadores em educação; que transforma todos os espaços físicos em lugar de aprendizagens significativas e de vivências efetivamente democráticas (SIILVA, 2009, p. 223).

A autora aponta alguns indicadores da qualidade social na educação, dividindo-os em determinantes externos e determinantes internos que 208 contribuem para referência da qualidade escolar. Com relação aos determinantes do lado de fora da escola, tem-se:

a) Fatores socioeconômicos, como condições de moradia; situação de trabalho ou de desemprego dos responsáveis pelo estudante; renda familiar; trabalho de crianças e de adolescentes; distância dos locais de moradia e de estudo.

b) Fatores socioculturais, como escolaridade da família; tempo dedicado pela família à formação cultural dos filhos; hábitos de leitura em casa; viagens, recursos tecnológicos em casa; espaços sociais frequentados pela família; formas de lazer e de aproveitamento do tempo livre; expectativas dos familiares em relação aos estudos e ao futuro das crianças e dos jovens.

c) Financiamento público adequado, com recursos previstos e executados; decisões coletivas referentes aos recursos da escola; conduta ética no uso dos recursos e transparência financeira e administrativa.

d) Compromisso dos gestores centrais com a boa formação dos docentes e funcionários da educação, propiciando o seu ingresso por concurso público, a sua formação continuada e a valorização 
da carreira; ambiente e condições propícias ao bom trabalho pedagógico; conhecimento e domínio de processos de avaliação que reorientem as ações (SILVA, 2009, p. 224, grifo da autora).

Internamente à escola, a autora traz elementos como:

[...] a organização do trabalho pedagógico e gestão da escola; os projetos escolares; as formas de interlocução da escola com as famílias; o ambiente saudável; a política de inclusão efetiva; o respeito às diferenças e o diálogo como premissa básica; o trabalho colaborativo e as práticas efetivas de funcionamento dos colegiados e/ou dos conselhos escolares (SILVA, 2009, p. 224).

No entanto, para que a educação avance nesse sentido, é preciso que "Processos de avaliação alternativos sejam exercitados com os atores da escola e da comunidade", processos esses pautados no diálogo entre diferentes pessoas "[...] unidas em torno de um projeto comum" (SORDI, 2012, p. 165).

Trata-se, portanto, de construir uma estratégia alternativa que recoloque os processos de medição de desenvolvimento dos alunos em seu devido lugar - desgastados que foram pelas políticas neoliberais ávidas por premiar e punir professores - e os associe a um processo (institucional) destinado a levar em conta o desempenho dos alunos como parte de um conjunto mais amplo de informações da realidade das escolas, favorecendo a reflexão e a organização dos trabalhadores em cada uma delas (FREITAS; SORDI; MALAVASI; FREITAS, 2012 , p. 67).

Assim, entende-se que é a comunidade local das escolas "[...] que pressionará os eventuais servidores públicos lenientes a assumir o verdadeiro "espírito de serviço público" onde o atendimento indiferenciado é pedra fundamental" (FREITAS, L.; SORDI; MALAVASI; FREITAS, H. 2012 p. 67).

$\mathrm{Na}$ mesma direção, Mendes (2012, p. 171) compreende as Avaliações Institucionais Participativas (AIP) como uma opção de ruptura e enfrentamento ao modelo neoliberal. Para a autora, nessa concepção, a escola "[...] a partir de uma ação de autoavaliação participativa, torna-se capaz de olhar criticamente para si mesma, redefinindo caminhos para alcançar a qualidade desejada [...]", ou seja, as AIPs são como uma resposta do coletivo da escola na construção da qualidade educacional. 
A autora supracitada apresenta resultados da implementação de uma política de Avaliação Institucional da Secretaria Municipal de Educação de Campinas, São Paulo, para as escolas do ensino fundamental. Por meio da formação de Comissões Próprias de Avaliação (CPA), o processo participativo foi implementado em 40 escolas da rede municipal. As considerações da autora apontam que as iniciativas "[...] denotam processos participativos ancorados na defesa da qualidade básica"; que "[...] a AIP dependerá muito do modo como é realizada essa ação pelas escolas"; e ainda que "[...] há indícios de a AIP, na rede, ser fortemente formativa para todos os segmentos envolvidos [...] potencializando momentos de autoavalição por meio da reflexão e do diálogo entre os diversos segmentos da escola".

A conclusão da autora é de que "[...] a opção da avaliação institucional em ter a escola como referência revela-se estratégia potente de contra-regulação, pois possibilita aprendizagens que se encaminham para o estabelecimento de pactos de qualidade negociada com os atores locais [...]" inferindo que "[...] processos de constituição de avaliação institucional, pautados por princípios democráticos, ancorados na qualidade negociada, provocaram mudanças, mesmo que pontuais para a rede de Campinas" 210 (MENDES, 2012, p. 192-193).

Importante ressaltar, ainda, que existe a clareza de que é necessário potencializar todas as formas de participação nas escolas, como, por exemplo, os Conselhos Educacionais, que também podem se tornar espaços de negociação e abrir possibilidades para construção da qualidade social da educação.

Para seguir esse outro caminho, ou seja, para que o processo avaliativo tenha um caráter formativo, é imprescindível que se tenha em mente os requisitos da qualidade negociada, quais sejam:

[...] a qualidade tem uma natureza transacional;

[...] a qualidade tem uma natureza participativa;

[...] a qualidade tem uma natureza auto-reflexiva;

[... ] a qualidade tem uma natureza contextual e plural;

[...] a qualidade é um processo;

[...] a qualidade tem uma natureza transformadora (BONDIOLI, 2004, p. 14). 
Fabiana Alvarenga Filipe | Regiane Helena Bertagna

Ou seja,

Valorizamos o contexto de práticas no qual há espaços de autonomia, de insubordinação, de apropriação e recontextualização. Ali ocorrem as operações de recepção, microrresistências, inércias, diferentes modos de praticar que são metáforas da ordem estabelecida e que manifestam, a um só tempo, o exercício e a burla da lei e da norma. Valorizamos o contexto das práticas onde se constrói a qualidade da educação, uma qualidade que envolve, a um só tempo, qualidade de rendimento, de gestão, de projeto político pedagógico; uma qualidade social que inclui necessariamente negociações (WERLE, SCHEFFER; MOREIRA (2012, p. 26)

Dessa forma, é importante que a comunidade escolar compreenda o papel da avaliação, visto que é, por meio da coletividade que existe a possibilidade de transformação da instituição, no intuito de alcançar a qualidade social.

Percebe-se que, para a compreensão do papel da avaliação, é necessário considerar a relação entre a educação e a sociedade e, antes de tudo, refletir acerca da função social da educação, que pode servir à manutenção da ordem vigente (se considerada como mercadoria) ou na emancipação dos indivíduos (se considerada como direito para o exercício da cidadania).

Sabe-se que os três níveis de avaliação (avaliação em larga escala, avaliação institucional e avaliação do processo de ensino-aprendizagem) devem ser trabalhados de forma integrada. Nesse sentido, corroboramos as ideias de que

[...] a avaliação de sistema é um instrumento importante para monitoração das políticas públicas e seus resultados devem ser encaminhados, como subsídio, à escola para que, dentro de um processo de avaliação institucional, ela possa consumir estes dados, validá-los e encontrar formas de melhoria. A avaliação institucional fará a mediação e dará, então, subsídios para avaliação de sala de aula, conduzida pelo professor. Entretanto, sem se criar este mecanismo de mediação, o simples envio ou disponibilização de dados em um site não terá um mecanismo seguro de reflexão sobre os mesmos. Os dados podem até ter legitimidade técnica, mas Ihes faltará legitimidade política (FREITAS; SORDI; MALAVASI; FREITAS, 2012, p. 65, grifo dos autores). 
As avaliações educacionais devem ser pensadas por todos os atores envolvidos no processo educacional, considerando que é coletivamente que são construídos os parâmetros da qualidade educacional que efetivamente, almejamos.

$\bigcirc$ conceito de qualidade negociada, "[... traz a dimensão da mudança, da participação" (SORDI; FREITAS, 2013, p. 89). Entretanto, é válido salientar que, quando se fala em "negociação", corrobora-se com as ideias de Sordi (2012a, p. 489) que tal termo "[...] causa certo desconforto no campo da educação. Fruto da visão mercadológica que percorre esta área, observamos que o uso de palavras que parecem reforçar o viés mercantilista é objeto de crítica por parte de alguns".

Dessa forma, concorda-se com a autora que:

Negociar, no âmbito da política de AIP, não pode ser entendido como sinônimo de barganha realizada à custa de prejuízo imposto a terceiros, sobretudo aqueles segmentos mais fragilizados no diálogo, exatamente pelo jogo assimétrico das relações de poder que os envolvem. Trata-se de legitimar a ideia de que atores diferentemente situados no projeto da escola podem, pelo diálogo, estabelecer negociações em torno dos problemas a resolver e das metas a atingir, permitindo-se demandas bilaterais (SORDI, $2012 \mathrm{a}$, p. 489-490).

Pensando a avaliação e a qualidade no âmbito educacional de forma participativa e negociada, emerge outra forma de responsabilização, qual seja, a "responsabilização participativa", que "Implica exercitar o coletivo da escola em processos de apropriação dos problemas do cotidiano e refletir sobre o futuro, principal função dos processos avaliativos" (SORDI; FREITAS, 2013 , p. 911.

Compreende-se que as políticas participativas requerem um esforço no sentido de que todos os atores escolares se apropriem de seus problemas, reflitam sobre eles e proponham alternativas para transformação; as responsabilidades devem existir, mas devem ser atribuídas a todos os envolvidos no desafio de construir a qualidade educacional, incluindo o poder público.

Essas políticas enfatizam que não há, apenas, um caminho a seguir. Mais do que isso, assinalam que existem formas de resistência que podem 
ser trabalhadas dentro do sistema (im)posto, inclusive com a apropriação dos dados fornecidos por esse sistema.

\section{Considerações finais}

Com base na contextualização histórico-política da centralidade das avaliações em larga no Brasil e no estado de São Paulo, foi possível constatar que tal unidade federativa, em consonância com a reforma pautada no ideário neoliberal, propulsionada pelo PDRAE em âmbito federal, instituiu o SARESP na década de 1990, visando promover uma cultura avaliativa no estado de São Paulo.

Da análise dos documentos, realizada com base nos referenciais teóricos adotados, infere-se que o estado de São Paulo trabalha, desde a década de 1990, para a manutenção e o aprofundamento de uma política de caráter neoliberal no campo educacional, cabendo ressaltar que a Resolução SE 74, de 6 de novembro de 2008, avança no sentido de imprimir centralidade ao SARESP, que compõe o IDESP e que, por sua vez, está atrelado à BR. Destaca-se, ainda, com base nos documentos analisados, o CIMA, comitê instituído pela Resolução SE 42, de 14 de julho de 2009 (SÃO PAULO, 2009) e que possui um grande papel de organizar e disseminar os resultados do SARESP, dando destaque ao sistema de avaliação do estado de São Paulo.

Os documentos analisados evidenciaram ainda que as avaliações em larga escala, da forma como estão sendo utilizadas potencializam a abertura à tríade "responsabilização, meritocracia e privatização" discutida por Freitas (201 1). Nesse sentido, o estado de São Paulo, a partir dos resultados de IDESP classifica as escolas, e, de acordo com o mérito, premia as "melhores" e responsabiliza aquelas que não conseguiram atingir a meta proposta.

Destaca-se ainda, a fragilidade na política de BR ISOUSA; MAIA; HAAS, 2014), que, ao recalcular as metas do IDESP, premia escolas que estão com o índice mais baixo do que outras escolas que mantiveram seu IDESP e, não recebem o bônus. Além da problemática em relação ao recebimento do bônus, o recálculo das metas faz com que a meta final fique mais distante de ser atingida.

É provável que o índice, da forma como está sendo utilizado, não induz a melhoria da qualidade educacional, mas possui a função de 
responsabilizar as escolas, que, por determinantes que extrapolam ao controle dos seus profissionais, não conseguem alcançar as metas.

Dessa forma, a BR, além de ser uma política que não potencializa a qualidade do trabalho das escolas, pode promover a competitividade entre os profissionais da educação, segregando-os. Portanto, a BR é uma política que não possui a potencialidade de fazer com que a coletividade da unidade escolar participe da construção da qualidade educacional, mas, contraditoriamente, promove a naturalização de relações na escola que exprimem um determinado entendimento de construção da qualidade, por meio de competitividade.

Em face do exposto, é possível afirmar que, no estado de São Paulo, as avaliações, em larga escala, induzem a uma concepção de qualidade educacional pautada na quantificação de resultados. Verifica-se que a melhoria da qualidade aparece diversas vezes nos documentos com uma interpretação reducionista, como, por exemplo, a Resolução SE 41, de 31 de julho de 2014 (SÃO PAULO, 2014 b) que traz consigo a preocupação com a qualidade educacional traduzida pelo IDESP.

É possível afirmar que a concepção de qualidade educacional, impul-

214 sionada pelas avaliações em larga escala e que emana dos documentos parece dar credibilidade ao processo que traduz a qualidade da educação em números e a "publicidade e transparência" parecem validar toda essa "lógica".

Nesse contexto, pode-se afirmar que o governo do estado de São Paulo intensifica a concepção de que as avaliações em larga escala são os instrumentos que verificam (medem) a qualidade educacional.

Com base na análise dos dados, percebe-se que o governo do estado de São Paulo sempre considerando o êxito, o sucesso obtido em suas políticas, a necessidade de melhorar a qualidade da educação, dispara novas normas, aprofundando a concepção gerencialista de cunho neoliberal na agenda educacional.

Compreende-se que a estratégia avaliação-informação-premiação lou medida-classificação-punição), utilizada pelo estado de São Paulo, é inerente ao ideário neoliberal que permeia as políticas educacionais do estado de São Paulo desde a década de 90, com o governo de Mário Covas que iniciou o 
projeto de implementação da política gerencialista, que teve e tem continuidade e aprofundamento com seus sucessores.

A naturalização da meritocracia, da competitividade, evidenciada pelos documentos oficiais do estado de São Paulo, possibilita o controle do processo educativo por meio dos testes. Isso torna possível a responsabilização e a transposição da lógica de mercado (gerencial), portanto, da esfera privada para a esfera pública, centralizadas no cumprimento das metas estabelecidas.

Apesar dos apontamentos (reducionistas) evidenciados na concepção de qualidade educacional nos documentos oficiais do estado de São Paulo, existe a compreensão de que o conceito de qualidade negociada (BONDIOLI, 2004; SORDI; FREITAS, 2013) traz a ideia de mudança, de melhoria, a partir da participação dos atores escolares, possibilitando um novo olhar para avaliação educacional. A Qualidade negociada construída coletivamente por meio da Avaliação Institucional Participativa (MENDES, 2012) deve ser a instância mediadora das avaliações da aprendizagem e das avaliações em larga escala.

Urge considerar que, apesar das evidências constantes dos documentos oficiais, que direcionam a qualidade educacional voltada para uma concepção mercadológica, eles também revelam as contradições que sinalizam possibilidades de resistência, visando recolocar a educação na esfera dos direitos sociais.

\section{Referências}

AFONSO, Almerindo Janela. Avaliação educacional: regulação e emancipação. 2 ed. São Paulo: Cortez, 2000.

ANDRÉ, Marli Eliza Dalmazo Afonso de. Estudo de caso em pesquisa e avaliação educacional. Brasília: Liberlivros, 2005.

ARCAS, Paulo Henrique. SARESP e progressão continuada: implicações na avaliação escolar. Estudos em Avaliação Educacional, São Paulo, p. 21, n. 47, p. 473-488, set./dez. 2010. Disponível em: hitp://publicacoes.fcc.org.br. Acesso em: 24 fev. 2014.

BARDIN, Laurence. Análise de conteúdo. Tradução Luís Antero Reto e Augusto Pinheiro. 4. ed. Lisboa: Edições 70/LDA, 2010. 
A concepção de qualidade educacional impulsionada pelas avaliações externas no estado de São Paulo

BARROS, Maria Camila Mourão Mendonça; TAVARES, Priscila de Albuquerque; MASSEI, William. O desenvolvimento da educação no estado de São Paulo. Perspect, São Paulo, v. 23, n. 1, p. 42-56, jan./jun. 2009. Disponível em: www.scielo.br. Acesso em: 28 set. 2015.

BERTAGNA, Regiane Helena. Avaliação e progressão continuada: o que a realidade desvela. Pro-Posições, Campinas, v. 21, n. 63, p. 193-218, set./dez. 2010.

BONDIOLI, Anna. O projeto pedagógico da creche e a sua avaliação: a qualidade negociada. Campinas: Autores Associados, 2004.

CASTRO, Maria Helena Guimarães de. A consolidação da política de avaliação básica no Brasil. Meta: Avaliação, Rio de Janeiro, v. 1, n. 3, p. 271-296, set./dez. 2009.

DANTAS, Gisele Kemp Galdino. Política educacional paulista (1995-2012): dos primórdios da reforma empresarial à consolidação do modelo gerencial. 2013. 153f. Tese (Doutorado em Educação) - Programa de Pós-Graduação em Educação, Faculdade de Filosofia e Ciências, Universidade Estadual Paulista, Marília, 2013.

FREITAS Luiz Carlos; SORDI, Mara Regina Lemes de; MALAVASI, Maria Márcia Sigrist; FREITAS, Helena Costa Lopes de. Avaliação educacional: caminhando pela contramão. 4. ed. Petrópolis: Vozes, 2012.

216 FREITAS, Luiz Carlos de. Apresentação. In: FREITAS, Luiz Carlos de. Políticas públicas de responsabilização na educação (Dossiê). Educação \& Sociedade, Campinas, v. 33, n. 119 , p. 345-351, abr./jun. 2012.

Responsabilização, meritocracia e privatização: conseguiremos escapar ao neotecnicismo?. In: SEMINÁRIO DE EDUCAÇÃO BRASILEIRA, 3, 2011 . Anais... Campinas, 2011 . Disponível em: http://www.cedes.unicamp.br. Acesso em: 28 maio 2013.

GIL, Antonio Carlos. Métodos e técnicas de pesquisa social. 6. ed. São Paulo: Atlas, 2008. LAMMOGLIA, Bruna. O sistema de avaliação de rendimento escolar do estado de São Paulo (SARESP) em escolas da rede estadual de ensino. 2013. 479f. Tese (Doutorado em Educação Matemática) - Programa de Pós-Graduação em Educação Matemática, Instituto de Geociências e Ciências exatas, Universidade Estadual Paulista, Rio Claro, 2013.

LOUREIRO, Bráulio Roberto de Castro. Reforma educacional neoliberal: uma análise política da concessão de bônus-mérito do governo José Serra (2007-2010) aos professores da rede estadual paulista. 2011 . 130f. Dissertação (Ciências Sociais) - Programa de PósGraduação em Ciências Sociais, Faculdade de Filosofia e Ciências, Universidade Estadual Paulista, Marília, 2011. 
MENDES, Geisa do Socorro Cavalcanti Vaz. Avaliação institucional na escola pública: construções possíveis à contrarregulação. In: FREITAS, Luiz Carlos de; MALAVASI, Maria Marcia Sigrist; SORDI, Mara Regina de; MENDES, Geisa do Socorro Cavalcanti (Org.). Avaliação e políticas públicas educacionais: ensaios contrarregulatórios em debate. Campinas: Leitura Crítica, 2012.

OLIVEIRA JÚNIOR, Rafael Gabriel de. Sistema de avaliação de rendimento escolar do estado de São Paulo: um estudo a partir da produção científica brasileira (1996-2011). 2013. 152f. Dissertação (Mestrado em Educação) - Programa de Pós-Graduação em Educação, Pontifícia Universidade Católica de Campinas. Campinas, 2013.

RUSSO, Miguel Henrique. Reforma da educação no estado de São Paulo: dimensões político-pedagógica e reforma curricular. In: IV CONGRESSO IBERO-AMERICANO DE POLIITICA E ADMINISTRAÇÃO DA EDUCAÇÃO, 4 / CONGRESSO LUSO BRASILEIRO DE POLÍTICA E ADMINISTRAÇÃO DA EDUCAÇÃO, 6, 2014. Porto. Anais... Escola Superior do Instituo Politécnico do Porto, Porto: 2014. Disponível em: http://anpae.org.br/IBERO_ AMERICANO_IV/GT6/GT6_Comunicacao/MiguelHenriqueRusso_GT6_integral.pdf. Acesso em: 14 out. 2015.

SÃO PAULO (Estado). Decreto n 53.667, de 7 de novembro de 2008. Altera e acrescenta dispositivos que especifica no Decreto n 51.672 , de 19 de março de 2007, que regulamenta, no âmbito do Estado de São Paulo, a gestão dos recursos originários do Fundo de Manutenção e Desenvolvimento da Educação Básica e de Valorização dos Profissionais da Educação FUNDEB e institui o Conselho de Acompanhamento e Controle Social sobre a distribuição, a transferência e a aplicação dos recursos do fundo, e dá providências correlatas. Diário Oficial [do] Estado de São Paulo, São Paulo, SP, 8 nov. 2008a. Disponível em: http://www.al.sp.gov.br. Acesso em: 24 set. 2014.

Lei Complementar 1.078, de 14 de dezembro de 2008. Institui Bonificação por Resultados - BR, no âmbito da Secretaria da Educação, e dá providências correlatas. Diário Oficial [do] Estado de São Paulo, São Paulo, SP, 18 dez. 2008c. Disponível em: < http:// www.al.sp.gov.br>. Acesso em: 26 jul. 2014.

Resolução SE-74, de 6 de novembro de 2008. Institui o Programa de Qualidade da Escola - PQE. [2008b]. Não paginado. Disponível em: http://www.educacao.sp.gov. br. Acesso em: 12 jan. 2015.

Resolução SE-76, de 7 de novembro de 2008. Dispõe sobre a implementação da Proposta Curricular do Estado de São Paulo para o Ensino Fundamental e para o Ensino Médio, nas escolas da rede estadual. [2008d]. Não paginado. Disponível em: http:// www.educacao.sp.gov.br. Acesso em: 12 jan. 2015. 
A concepção de qualidade educacional impulsionada pelas avaliações externas no estado de São Paulo

Resolução SE-42, de 14 de julho de 2009. Cria o Comitê Central de Informação, Monitoramento e Avaliação Educacional. [2009a]. Não paginado. Disponível em: http:// www.educacao.sp.gov.br. Acesso em: 12 jan. 2015.

Resolução SE-18, de 5 de fevereiro de 2010. Dispõe sobre a consolidação das diretrizes e procedimentos do Programa Escola da Família e dá providências correlatas. [2010]. Não paginado. Disponível em: hitp://www.educacao.sp.gov.br. Acesso em: 12 jan. 2015.

Resolução SE-41, de 31 de julho de 2014. Dispõe sobre a realização das provas de avaliação relativas ao Sistema de Avaliação de Rendimento Escolar do Estado de São Paulo - SARESP/2014. [2014b]. Não paginado. Disponível em: http://www.educacao. sp.gov.br. Acesso em: 12 jan. 2015.

Resolução SE-73, de 29 de dezembro de 2014. Dispõe sobre a reorganização do Ensino Fundamental em Regime de Progressão Continuada e sobre os Mecanismos de Apoio Escolar aos alunos dos Ensinos Fundamental e Médio das escolas estaduais. [2014a]. Não paginado. Disponível em: http://www.educacao.sp.gov.br. Acesso em: 12 jan. 2015.

SILVA, Maria Abádia da. Qualidade social da educação pública: algumas aproximações. Caderno Cedes, Campinas, v. 29, n. 78, p. $216-226$, maio/ago. 2009.

218 SORDI, Mara Regina Lemes de. A avaliação da qualidade da escola pública: a titularidade dos atores no processo e as consequências do descarte de seus saberes. In: FREITAS, Luiz Carlos de; MALAVASI, Maria Marcia Sigrist; SORDI, Mara Regina de; MENDES, Geisa do Socorro Cavalcanti (Org.). Avaliação e políticas públicas educacionais: ensaios contrarregulatórios em debate. Campinas: Leitura Crítica, 2012.

SORDI, Mara Regina Lemes de. Implicações ético-epistemológicas da negociação nos processos de avaliação institucional participativa. Educação \& Sociedade, Campinas, v. 33, n. 119 , p. 485-510, abr./jun. 2012 a.

SORDI, Mara Regina Lemes de; FREITAS, Luiz Carlos de. Responsabilização participativa. Revista Retratos da Escola, Brasília, v. 7, n. 12, p. 87-99, jan./jun. 2013.

SOUSA, Sandra Zákia; MAIA, Marcia Vieira da; HAAS, Celia Maria. Avaliação, índices e bonificação: controvérsias suscitadas por dados da rede estadual paulista. Estudos em Avaliação Educacional, São Paulo, v. 25, n. 58, p. 188-209, maio/ago. 2014.

WERLE, Flávia Obino Corrêa; SCHEFFER, Lisandra Scheneider; MOREIRA, Marilan de Carvalho. Avaliação e qualidade social da educação. ETD - Educação Temática Digital, Campinas, v. 14, n. 2, p. 19-37, jul./dez. 2012. Disponível em: hitp://www.fae.unicamp.br/revista/index.php/etd/article/view/3193/pdf. Acesso em: 15 jul. 2013. 
Ms. Fabiana Alvarenga Filipe Universidade Estadual "Júlio de Mesquita Filho" - Rio Claro Doutoranda do Programa de Pós-Graduação em Educação Grupo de Estudos e Pesquisas em Políticas Educacionais - GREPPE E-mail | fabiana_alvarenga@yahoo.com.br

Profa. Dra. Regiane Helena Bertagna Universidade Estadual "Júlio de Mesquita Filho" - Rio Claro

Departamento de Educação Programa de Pós-Graduação em Educação Grupo de Estudos e Pesquisas em Políticas Educacionais - GREPPE E-mail | regiane@rc.unesp.br

Recebido 27 out. 2017 Aceito 23 nov. 2017 